\title{
Aceitação de brinquedos de madeira fabricados com resíduos da arborização urbana
}

Luiz Fernando Pereira Bispo ${ }^{1}$, Adriana Maria Nolasco ${ }^{2}$, Debora Kilngenberg ${ }^{3}$, Ananias Francisco Dias Júnior ${ }^{4}$, Elias Costa de Souza ${ }^{5}$

1 Universidade de São Paulo, Eng. Florestal, luiz.bispo@alumni.usp.br

2 Universidade de São Paulo, Profa. Dra. do Depto. de Ciências Florestais, amnolasc@usp.br

3 Universidade de São Paulo, Eng. Florestal, Mestranda do PPG em Recursos Florestais, debora.klingenberg@usp.br

${ }_{4}^{4}$ Universidade Federal do Espírito Santo, Prof. Dr. Do Depto. de Ciências Florestais e da Madeira, ananias.dias@ufes.br

${ }^{5}$ Universidade de São Paulo, Eng. Florestal, Doutorando do PPG em Recursos Florestais, eliasrem@usp.br

\begin{abstract}
RESUMO: Os resíduos do manejo da arborização urbana são comumente aproveitados em compostos orgânicos ou lenha, mas possuem grande potencial de valorização em pequenos objetos de madeira, como brinquedos. Essa é uma alternativa que agrega mais valor ao resíduo madeireiro, pode incentivar novos empreendimentos, geração de postos de trabalho e renda. Nesse contexto, é importante compreender o real potencial que esses objetos têm no mercado, se eles serão bem aceitos e também quais os requisitos mais adequados em relação à expectativa do público consumidor. $O$ objetivo da pesquisa foi avaliar a aceitação do público consumidor (crianças de 2 a 7 anos, seus pais e também educadores) em relação a brinquedos produzidos com três espécies da arborização urbana comuns no Estado de São Paulo. Foi possível concluir que, a partir de algumas melhorias quanto ao design, escolha de espécies e processo de fabricação dos brinquedos, é possível utilizar resíduos da arborização urbana na produção destes pequenos objetos de madeira. Nesta pesquisa notamos que as crianças da faixa etária estudada são mais atraídas a brinquedos coloridos que naturais, mas que houve boa aceitação dos brinquedos fabricados com resíduos madeireiros da arborização urbana. Os pais e educadores das crianças de 2 a 7 anos de idade também aceitaram bem os brinquedos, mas com certas ressalvas quanto ao design e escolha de espécies adequadas para cada finalidade. Os preços sugeridos foram bem inferiores ao que é praticado no mercado de brinquedos de madeira atualmente, o que indica o não conhecimento dos custos e dificuldades de se trabalhar com esse tipo de material, ou do preço praticado.
\end{abstract}

PALAVRAS-CHAVE: Aproveitamento de resíduos, pequenos objetos de madeira, brinquedos de madeira

\begin{abstract}
The residues from tree management of urban forests are commonly used in organic compounds or as firewood, but have great potential for recovery in small wooden objects, such as toys. This is an alternative that adds more value to wood waste, can encourage new ventures, job creation and income. In this context, it is important to understand the real potential that these objects have on the market, whether they will be well accepted and also what are the most adequate requirements in relation to the expectations of the consuming public. The objective of the research was to evaluate the acceptance of the consuming public (children from 2 to 7 years old, their parents and also educators) in relation to toys produced with three common species of urban forestry in the State of São Paulo. It was possible to conclude that, based on some improvements regarding the design, choice of species and the toy manufacturing process, it is possible to use waste from urban forests in the production of these small wooden objects. In this research we noticed that children of the studied age group are more attracted to colorful toys than natural ones, but that there was good acceptance of toys manufactured with the wood residues. The parents and educators of children from 2 to 7 years old also accepted the toys well, but with certain reservations regarding the design and choice of species, that should be suitable for each purpose. The suggested prices were much lower than what is practiced in the wooden toy market today, which indicates the lack of knowledge of the costs and difficulties of working with this type of material, or the price practiced.
\end{abstract}

KEYWORDS: Waste recovery, small wooden objects, wood toys

\section{INTRODUÇÃO}

As árvores, no ambiente urbano, podem amenizar as temperaturas, reduzir o impacto da chuva no solo, sequestrar e estocar carbono, além de sua função estética e de proporcionar bem-estar e melhorar a saúde da população, mas apesar dos seus benefícios, seus resíduos ainda são recursos subutilizados (Nowak e Greenfield, 2018). O manejo das árvores nas cidades gera grandes quantidades de resíduos lenhosos (troncos, galhos e raízes) e folhas. Esses são comumente aproveitados em compostos orgânicos ou na geração de energia (Meira, 2010). 
Apesar de já haverem algumas iniciativas de aproveitamento, parte dos resíduos poderia ser valorizada em produtos de maior valor agregado como os pequenos objetos de madeira (Sousa, 2019; Bartholomeu et al., 2020). Para viabilizar essa alternativa, é necessária a caracterização da madeira das espécies utilizadas na arborização urbana; o desenvolvimento e testes de produtos; a capacitação de mão de obra; o investimento em infraestrutura de produção; o desenvolvimento de um plano de triagem dos resíduos; estudos que avaliem a secagem e armazenamento apropriado do material; e o desenvolvimento de estratégias de marketing adequadas (Meira, 2010).

Uma das alternativas viáveis dentre os pequenos objetos de madeira é a produção de brinquedos. Estudos sobre o uso de resíduos madeireiros na fabricação de brinquedos já foram desenvolvidos usando resíduos das indústrias de móveis de madeira, de serrarias e da fabricação de esquadrias (Costantin, 2018); dos resíduos da arborização urbana (Meira, 2010); dos resíduos de marcenarias (Nejeliski et al., 2016; Fonseca et al., 2018); e de painéis de madeira (Abreu et al., 2009).

Desde a Antiguidade Clássica existem registros de brinquedos de madeira, fabricados artesanalmente pela família, em casa, e posteriormente por artesãos especializados nesse tipo de produto, principalmente na Alemanha (Barata, 2018).

No século XIX já era comum professores utilizarem nas escolas peças e brinquedos de madeira como forma de ensino e desenvolvimento das capacidades cognitivas das crianças. Desde a segunda metade desse mesmo século, os brinquedos passaram a ser objetos de consumo e não mais apenas lúdicos (Macedo, 2013).

Atualmente, no mundo todo, os brinquedos são produzidos majoritariamente com materiais plásticos, produzidos principalmente na China (Oliveira, 2019). O plástico é um material barato e de longa duração, mas a sua introdução no mercado ocasionou um distanciamento da realidade em decorrência da artificialização dos brinquedos e o esquecimento da história hereditária dos brinquedos de madeira, que fizeram parte da cultura e formação pedagógica de diversas crianças ao redor do mundo (Tanner, 2009; Oliveira, 2019).

Além disso, no século XXI houve uma tendência de produção de brinquedos homogêneos e globalizados e dispositivos tecnológicos que tornaram os brinquedos de madeira cada vez mais distantes do mercado e das brincadeiras das crianças.

Seguindo as tendências recentes de redução do uso do plástico e os princípios de desenvolvimento sustentável e produtos ecológicos, a madeira volta a ser um dos focos e materiais de interesse, pois brinquedos produzidos com madeira são muito duráveis, sólidos, orgânicos, resistentes e leves, de acordo com a espécie escolhida para fabricação, além de serem feitos com um material biodegradável e renovável (Barata, 2018).

Segundo Piaget (1995), o desenvolvimento e a reflexão abstrata acontecem devido às conexões que a criança cria não com os objetos em si, mas na coordenação das ações ou operações das atividades, como por exemplo com o objeto em mãos.

O estimulo da brincadeira desperta nas crianças reflexões, conexões, sentimentos, ideias, raciocínios, movimentos e sentidos (Carvalho, 2016) e um brinquedo produzido com madeira pode estimular o "brincar" pela interação homem-natureza de modo efetivo, aproximando a criança de um material natural, usado há centenas de anos na educação e desenvolvimento infantil.

Unindo o aproveitamento de resíduos madeireiros do manejo da arborização urbana e o resgate do brincar com objetos de madeira, o objetivo dessa pesquisa foi resgatar e desenvolver alguns brinquedos de madeira, fabricando protótipos com resíduos de três espécies comumente utilizadas na arborização de cidades brasileiras e avaliar sua aceitação por pais, educadores e crianças de 2 a 7 anos de idade.

\section{MATERIAIS E MÉTODOS}

\subsection{Público}

A teoria do desenvolvimento mental das crianças descrita por Jean Piaget (1999) parte do princípio de que o ser humano potencializa seu método de aprendizagem quando a informação e o pensamento são desenvolvidos de maneira construtiva.

Ele divide o desenvolvimento humano em quatro períodos: sensório-motor (0 - 2 anos); pré-operatório (2 - 7 ou 8 anos); operatório-concreto (8 - 11 anos) e operatório-formal (8 - 14 anos).

O período dos 2 aos 7 ou 8 anos, descrito como préoperatório é quando a criança está em uma fase simbólica, de apropriação da linguagem e também da significação de objetos (Rosa et al., 2018). Por este motivo, foi escolhida essa faixa etária para desenvolver os brinquedos e avaliar sua aceitação pelas crianças, pais e educadores.

\subsection{Escolha de espécies}

Foram selecionados os resíduos de poda de três espécies da arborização urbana do Estado de São Paulo, sendo elas a Schinus molle (aroeira-salsa), Spathodea campanulata (espatódea) e Handroanthus heptaphyllus (ipê-rosa). Essas espécies são comuns na silvicultura urbana tanto no Estado de São Paulo como em outras regiões de Mata Atlântica (Silva Filho, 2009; Freitas et al., 2020).

Dentre as características mais importantes para a seleção de madeiras para o desenvolvimento de um produto está a densidade básica da madeira, em 
decorrência da sua correlação com diversas outras propriedades físicas e mecânicas (Nascimento et al., 2017). A espécie Schinus molle apresenta densidade básica de $0,478 \mathrm{~g} / \mathrm{cm}^{3}$, a Spathodea campanulata de $0,309 \mathrm{~g} / \mathrm{cm}^{3}$ e Handroanthus heptaphyllus de 0,706 $\mathrm{g} / \mathrm{cm}^{3}$ (Bispo, 2017).

Essas espécies foram selecionadas para avaliar a aplicação de madeiras de diferentes densidades e consequentemente o peso dos brinquedos em relação ao design e a partir da avaliação das crianças, pais e educadores.

\subsection{Brinquedos utilizados}

Os brinquedos usados para a pesquisa foram produzidos a partir dos resíduos de madeira dos galhos das espécies da arborização urbana selecionadas, o que foi possível devido à disponibilidade de matériaprima e à compatibilidade das dimensões dos brinquedos em relação aos resíduos. Sua produção foi baseada nos estímulos físico, cognitivo e afetivo das crianças de 2 a 7 anos e o desenvolvimento das habilidades nessa idade.

Para o estímulo físico, é necessário que o brinquedo desenvolva na criança as habilidades de noção de distância, espaço e lateralidade, além da coordenação motora grossa, que pode ser atendida por peças de boliche, blocos de construção, balde e pá, instrumentos musicais simples como xilofone, material para pintura e desenho.

Para o estímulo cognitivo, é importante o desenvolvimento da concentração, socialização, atenção, memória, foco, raciocínio lógico por associação de formas, criatividade, curiosidade, linguagem, observação e pensamento. Isso pode ser feito através de brinquedos como jogos em equipe, quebra-cabeça, bonecos, jogo da memória e dominó.

No caso do estímulo afetivo, a habilidade desenvolvida é relacionada à criatividade, sentimento, imitação, representação das pessoas e/ou objetos, relações sociais, realidade cotidiana, desejos e ansiedades, atendido por brinquedos como bonecos, carrinhos, trenzinhos e aldeias.

Foram usados nas pesquisas de opinião os seguintes brinquedos: vilinha, carrinho, boliche, quebra-cabeça em cubos, trem e bonecos (figura 1), atendendo os requisitos de brinquedos para crianças do período pré-operatório.

A vilinha, os carrinhos e o trem foram produzidos com a espécie Schinus molle, na forma natural ou usinada, com e sem pintura. No caso do boliche, os pinos foram produzidos com as três espécies (Schinus molle, Spathodea campanulata e Handroanthus heptaphyllus), sendo alguns rústicos, mantendo as características naturais do resíduo e outros com algumas operações de usinagem e beneficiamento. Os quebra-cabeças em cubos foram fabricados com e sem pintura, usando as espécies Spathodea campanulata e
Handroanthus heptaphyllus. O critério de escolha das espécies para a fabricação desses brinquedos foram o formato e dimensão dos galhos, a densidade da madeira e a facilidade de acabamento e pintura.
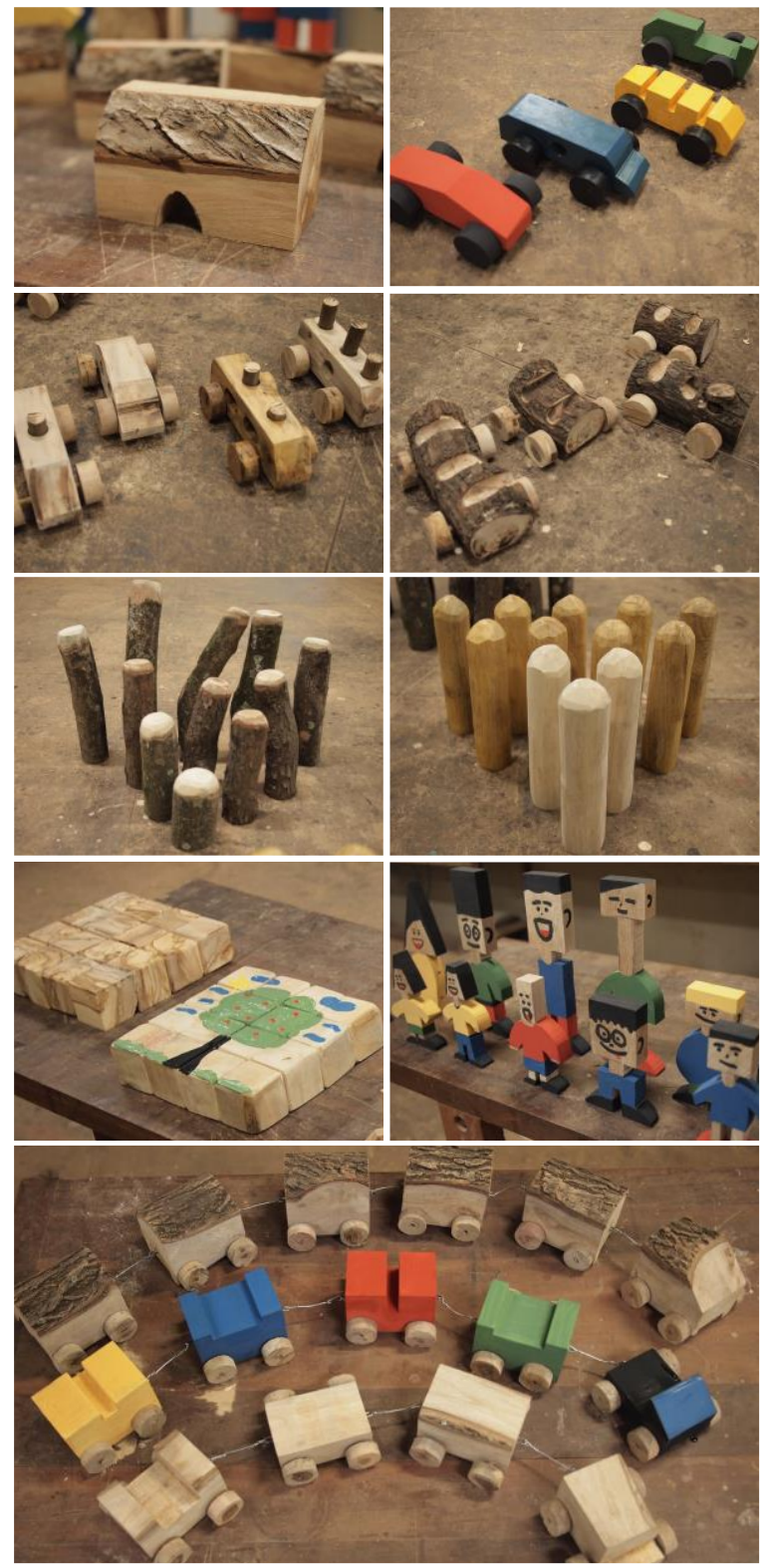

Figura 1: Brinquedos feitos com resíduos da arborização urbana utilizados para a pesquisa de aceitação e preferência. Fonte: Bispo, 2017.

\subsection{Pesquisa de opinião}

A pesquisa de opinião foi desenvolvida para testar a preferência dos consumidores quanto aos objetos avaliados (brinquedos de madeira produzidos com resíduos de galhos da arborização urbana) e sua aceitação de modo geral.

Para que as amostras fossem representativas, a pesquisa foi aplicada em duas escolas de educação infantil do município de Piracicaba, SP, e também no parque da Escola Superior de Agricultura "Luiz de Queiroz" da Universidade de São Paulo (ESALQ/USP). 
Foram abordadas três categorias de entrevistados: educadores, pais e crianças. No entanto, o foco principal foi o público consumidor e efetivos compradores, que geralmente são os pais das crianças.

Foram entrevistadas ao todo trinta e quatro (34) crianças, dezesseis (16) pais e seis (6) educadores, com devido consentimento dos entrevistados e das instituições participantes. Eles foram selecionados aleatoriamente, contemplando pessoas com diversos níveis de escolaridade, profissão e gênero. Foram elaborados três roteiros de entrevista (um para cada categoria dos entrevistados) para melhor entender cada público específico, suas preferências e aceitação do produto.

O roteiro elaborado para as crianças era mais focado nas preferências pessoais de cada uma em relação ao tipo de brinquedo, cores, acabamentos e também sobre a percepção da madeira como principal material utilizado. A entrevista foi feita apresentando os brinquedos para grupos de crianças avaliando sua reação inicial e ao conhecer melhor o produto. Aos poucos, durante o período em que elas estavam brincando, foram realizadas as perguntas.

Para os pais, a pesquisa foi um pouco mais extensa e focada nas suas preferências e comportamento de compras. Tanto para os pais quanto para os educadores, para os seis diferentes brinquedos, foi solicitado que aplicassem uma nota de 0 a 5 para cada um dos seguintes requisitos: uso dos materiais, cores, forma, peso, beleza, aspecto lúdico, ambiental, segurança, potencial de mercado e funcionalidade.

Para os pais e educadores ainda foi deixado um campo para sugestão de preços para cada objeto para posterior comparação com valor de o mercado de brinquedos similares de madeira.

\section{RESULTADOS E DISCUSSÃO}

Em relação ao nível de escolaridade, os pais entrevistados possuíam, em sua maioria (69\%), ensino superior completo, seguido de superior incompleto (13\%), ensino médio completo (12\%) e apenas ensino fundamental (6\%).

Dentre as crianças entrevistadas, $32 \%$ responderam já ter tido um brinquedo de madeira e $68 \%$ responderam negativamente à essa questão. Apesar desse resultado, $75 \%$ dos pais responderam positivamente quanto ter presenteado seus filhos com brinquedos de madeira; e 25\% nunca compraram brinquedos de madeira para as crianças.

É importante ressaltar que, quando comparados a brinquedos feitos de materiais plásticos, os brinquedos de madeira maciça apresentam algumas vantagens, como: menor possibilidade de engolir pedaços quebrados, estimula a imaginação das crianças, geralmente tem qualidade superior em termos de design, são fáceis de limpar, não contêm produtos químicos nocivos e são feitos de materiais renováveis (Madar et al., 2012; Rocha, 2018).

Os resultados da pesquisa aplicada para as crianças de 2 a 7 anos de idade indicam que sua aceitação é muito maior em relação aos brinquedos coloridos do que somente com a cor natural da madeira (figura 2) e, dentre as cores apresentadas nos objetos, a cor vermelha foi a preferida das crianças, seguida do azul, verde, preto e amarelo (figura 3).

A preferência por brinquedos coloridos pode estar relacionada ao estímulo visual que as cores vermelho, verde, amarelo, azul e preto podem proporcionar ao público infantil. As cores representadas nos brinquedos são aquelas com as quais é possível descrever qualquer outra nuance, conhecidas também por cores primárias psicológicas (Goldstein, 2010; Chaibub, 2017).

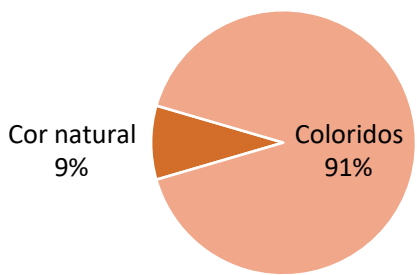

Figura 2: Preferência das crianças quanto aos brinquedos naturais ou coloridos.

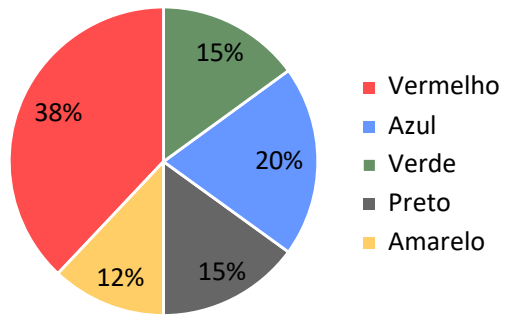

Figura 3: Preferência das crianças quanto as cores dos brinquedos.

Já foi constatado que tanto o público infantil quanto adulto, independente do gênero, aprecia muito as cores vermelho e azul, sempre relacionadas a aspectos emocionais positivos (Jonauskaite et al., 2019), sendo as duas mais votadas quanto a preferência de cor no presente estudo.

Não foram encontrados estudos recentes na literatura que comparem a preferência de brinquedos coloridos em relação aos que mantém a cor natural da madeira.

Ainda em relação às preferências das crianças entrevistadas, $88 \%$ responderam que preferem brincar com amigos e colegas e $12 \%$ preferem brincar sozinhos com os brinquedos.

Foi possível constatar que pouco mais que a metade dos pais entrevistados (56\%) não compram brinquedos para renovar o estoque para suas crianças em um período menor que um ano; $6 \%$ responderam que a frequência de troca de brinquedos é feita em intervalos anuais; $25 \%$ semestrais; $13 \%$ mensais e 
nenhum respondeu que faz compras de brinquedos semanalmente.

Por esse motivo, é muito importante que os pais adquiram brinquedos que sejam realmente duráveis, característica dos brinquedos de madeira maciça.

Ainda em relação aos hábitos de compra de brinquedos dos pais, $81 \%$ disseram que avaliam a função do brinquedo para tomar a decisão. Para a entrevista, pré-selecionamos alguns dos possíveis estímulos procurados nos brinquedos pelos pais entrevistados, sendo eles: a coordenação motora grossa (CMG) e a coordenação motora fina (CMF), a criatividade, a imaginação, o aprendizado (através de objetos com cores, números e letras), o desenvolvimento do raciocínio lógico, da curiosidade, dos sentidos (tato, audição e visão) e a socialização.

Os resultados que obtivemos indicam que os estímulos mais valorizados pelos pais nos brinquedos para crianças de 2 a 7 anos são a criatividade, CMF e CMG e a imaginação (figura 4).

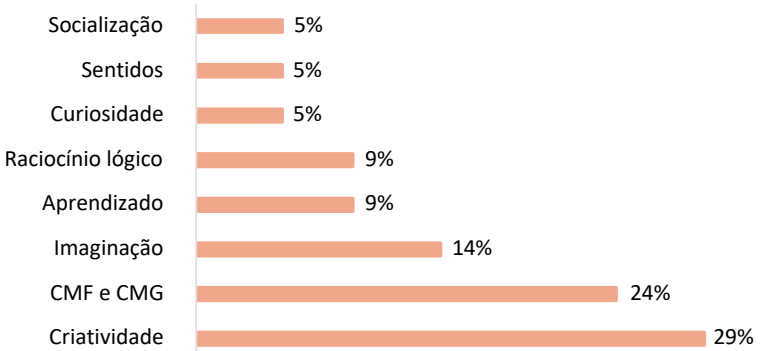

Figura 4: Estímulos que os pais buscam ao adquirir um brinquedo para seus filhos.

Quando em contato com os brinquedos produzidos com resíduos da arborização urbana, todas as crianças responderam que gostariam de ter um brinquedo de madeira.

Dos seis brinquedos, o que não recebeu nenhum voto de preferência das crianças foi a vilinha; em contraposição, os bonecos foram os preferidos de $29 \%$ e o trem de $26 \%$ das crianças (figura 5 ).

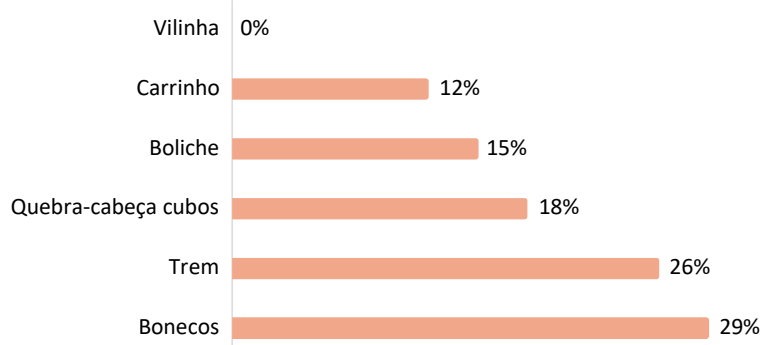

Figura 5: Brinquedos feitos com madeira da arborização urbana preferidos pelas crianças.

$\mathrm{Na}$ avaliação dos requisitos dos brinquedos, os 16 pais apresentaram médias semelhantes com os resultados fornecidos pelos 6 educadores e, de modo geral, os resultados foram bem positivos para todos os objetos apresentados (figura 6).

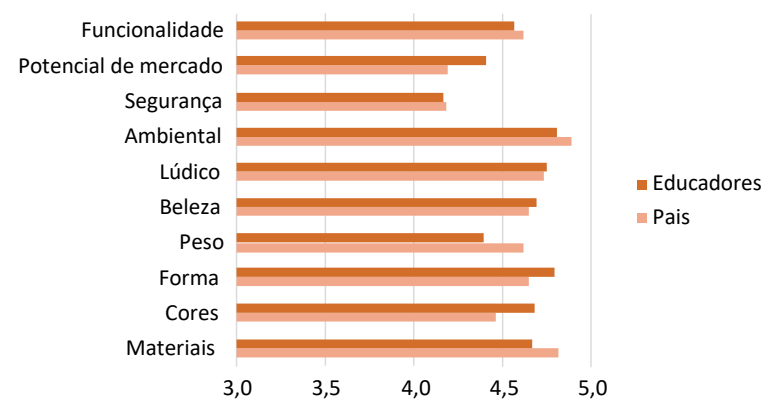

Figura 6: Notas de 0 a 5 para os brinquedos de madeira da arborização urbana quanto aos requisitos pré-estabelecidos.

Apesar da avaliação positiva para todos os requisitos selecionados, houveram algumas notas mais baixas dadas pelos educadores para peso, segurança, funcionalidade e potencial de mercado do boliche; e pelos pais quanto a segurança do boliche e do trenzinho. A maior preocupação ressaltada pelos pais é em relação ao perigo de ingestão de alguma peça que possa ser solta do trenzinho; e na queda dos pinos do boliche rústico, que no caso desse estudo foram feitos com madeira relativamente densa (ipêrosa), podendo machucar as crianças.

Já os educadores mencionaram que: (i) para alguns brinquedos as espécies mais densas podem não ser adequadas; (ii) é necessário que se tenha comprovação da legalidade da madeira; (iii) seria interessante para os compradores entenderem a origem do material (poda da arborização urbana) para se conscientizarem desse conceito; e (iv) que é necessário considerar o custo de produção dos brinquedos para poder avaliar sua viabilidade.

Ainda sugeriram algumas melhorias nos brinquedos apresentados, como evitar arestas retas e pontiagudas, se atentar ao peso dos objetos e também a peças de outros materiais e elementos mecânicos de fixação que possam se soltar no uso, como parafusos, por exemplo. Assim, é necessário se evitar peças que possam se desprender e ser ingeridas pelas crianças. Para essa finalidade específica, recomendou-se o uso de cordão encerado em substituição a arames e cabos metálicos.

Quando há esse tipo de peças ou em brinquedos menores, há geralmente a exigência da presença de um adulto para sua manipulação (Chaigar \& Madruga, 2015), porém é importante que o fabricante já evite esse tipo de material para confecção dos brinquedos. Todos os educadores afirmaram inserir em suas atividades pedagógicas brinquedos e objetos de madeira, principalmente por valorizar essa matériaprima, para ter diversidade de materiais manipulados pelas crianças, pela durabilidade e qualidade do produto, para conscientizar as crianças sobre a importância da natureza, e porque são brinquedos que estimulam o raciocínio lógico e a criatividade.

Os preços sugeridos pelos pais para a maioria dos brinquedos fabricados a partir dos resíduos da 
arborização urbana foram mais baixos que os já praticados no mercado produzidos de madeiras mais convencionais (Tabela 1). De maneira geral, os objetos que foram apresentados com diferentes tipos de acabamento (rústico; com operações de usinagem; e com pintura), os brinquedos rústicos sempre tiveram preço sugerido pelos pais e educadores menor que os demais, o que é válido considerando a quantidade de operações e materiais utilizados para sua produção.

Apenas o trenzinho teve preços médios sugeridos pelos pais e educadores semelhantes ao que se encontrou no mercado atualmente. Todos os demais apresentaram grande discrepância com a realidade, não sendo compatíveis com o mercado de brinquedos de madeira.

Tabela 1: Comparação da média de preço sugerido pelos consumidores e o que é praticado no mercado de brinquedos de madeira.

\begin{tabular}{|c|c|c|c|c|}
\hline \multirow{2}{*}{ Brinquedo } & \multirow{2}{*}{ Tipo } & \multicolumn{3}{|c|}{ Preço sugerido médio ( $\mathrm{R} \$$ ) } \\
\hline & & Pais & Educadores & Mercado \\
\hline \multicolumn{2}{|c|}{ Vilinha } & 38 & 25 & 45 \\
\hline \multirow{3}{*}{ Carrinho } & $\begin{array}{c}\text { Usinado e } \\
\text { pintado }\end{array}$ & 18 & 30 & \multirow{3}{*}{45} \\
\hline & Usinado & 15 & 25 & \\
\hline & Rústico & 15 & 25 & \\
\hline \multirow{2}{*}{ Boliche } & Usinado & 35 & 50 & \multirow{2}{*}{65} \\
\hline & Rústico & 23 & 30 & \\
\hline Quebra-cab & em cubos & 23 & 40 & 128 \\
\hline \multirow{3}{*}{ Trenzinho } & $\begin{array}{l}\text { Usinado e } \\
\text { pintado }\end{array}$ & 28 & 55 & \multirow{3}{*}{45} \\
\hline & Usinado & 25 & 45 & \\
\hline & Rústico & 18 & 35 & \\
\hline \multicolumn{2}{|c|}{ Bonecos } & 20 & 20 & 45 \\
\hline
\end{tabular}

É possível inferir que os pais e educadores entrevistados não têm consciência dos custos e dificuldades de se trabalhar com esse tipo de material, ou do preço praticado no mercado de brinquedos de madeira. De modo geral, os pais e educadores ressaltaram que os brinquedos de madeira eram muito interessantes em relação à sustentabilidade, qualidade, beleza e funcionalidade dos produtos.

Eles reconheceram e ressaltaram a importância da utilização de resíduos da arborização urbana para a produção de pequenos objetos de madeira, pois são provenientes de uma fonte de matéria-prima renovável e pode ajudar na conscientização da população quanto ao uso pedagógico da madeira e retomar a cultura de brinquedos de madeira que foi parcialmente substituída pelos materiais plásticos.

\section{CONCLUSÃO}

Foi possível concluir que, a partir de algumas melhorias quanto ao design, escolha de espécies e processos de fabricação dos brinquedos, é possível utilizar resíduos da arborização urbana na produção destes pequenos objetos de madeira.

Confirmou-se que as crianças de 2 a 7 anos, do período pré-operatório, segundo Piaget, são mais atraídas por brinquedos coloridos do que apenas pelos tons naturais da madeira, sendo a cor vermelha a preferida.

Ressalta-se que é necessário escolher materiais de densidade adequada com sua finalidade, evitar arestas e cantos vivos ou pontiagudos e peças que podem se desprender ou lascar, para melhorar a segurança dos brinquedos para manipulação das crianças de 2 a 7 anos.

A conscientização da população e a recuperação da cultura de se brincar com brinquedos de madeira é essencial para a disseminação desta ideia de aproveitamento de resíduos e também para possibilitar a venda desses materiais no mercado.

\section{AGRADECIMENTOS}

Agradecemos a todas as instituições, crianças, pais e professores que se dispuseram a participar dessa pesquisa.

\section{REFERÊNCIAS}

1. Nowak, D. J. \& Greenfield, E. J. (2018). US urban forest statistics, values, and projections. Journal of Forestry, v.116, n.3, p. 164-177.

2. Meira, A. M. de. (2010). Gestão de Resíduos da Arborização Urbana. Tese de Doutorado. Universidade de São Paulo (ESALQ/USP), Piracicaba, SP.

3. Sousa, C. M. (2019). Waste Valuing from Urban Wood Management Through Design: Ideas from the case of São Paulo. AGATHÓN - International Journal of Architecture, Art and Design, n.6, p.228-239.

4. Bartholomeu, C. S., Sousa, C. M. \& Brazolin, S. (2020). From invasive tree to raw material - a research on the potential use of leucena wood for product design. Estudos em Design, v. 28, n. 2, p. 155-169.

5. Costantin, A. (2018). Reaproveitamento de Resíduos de Madeira para o Desenvolvimento de Peças e Sistema de Encaixe para o Jogo de Tabuleiro Ticket to Ride. Monografia de conclusão de curso de Design na Universidade do Vale do Taquari - UNIVATES. 144p.

6. Nejeliski, D. M., Vieira, A. Z. Tescke, L. R. \& Rigo, F. C. (2016). Produção de Brinquedos a Partir de Resíduos de Marcenarias. Boletim Técnico-Científico do Instituto Federal Farroupilha, v.2, n.1.

7. Fonseca, E. S., Sanches, L. S., Gusmão Neto, J. J., Andreeta, A. B. \& Orives, A. M. L. G. (2018). Reutilização de resíduos de MDF de pequenas marcenarias da cidade de Itu - SP. 60 Congresso Internacional de Tecnologias para o Meio Ambiente.

8. Abreu, L. B., Mendes, L. M. \& Moreira da Silva, J. R. (2009). Aproveitamento de Resíduos de Painéis de Madeira Gerados pela Indústria Moveleira na Produção de Pequenos Objetos. Árvore, Viçosa-MG, v.33, n.1, p.171-177.

9. Barata, F. C. L. F. (2018). Dimensões da Relação da Criança com o Design do Brinquedo: um estudo sobre as preferências individuais e fatores associados. 
Dissertação de Mestrado. Universidade de Lisboa, Faculdade de Belas-Artes.

10. Macedo, B. L. (2013, Aug 18). Brincadeira de Criança: um assunto sério.

http://psibrunalouisemacedo.blogspot.com.br/2013/ 08/brincadeira-decrianca-um-assunto-serio.html 11. Oliveira, J. L. S. (2019). Formando a Infância: o papel do design na materialização da primeira infância através dos brinquedos. Dissertação de mestrado. Instituto de Artes da Universidade de Brasília.

12. Tanner, R. (2009). Why Wooden Toys are Better than Plastic for Children. http://unclebobsworkshop.webasyst.net/shop/blog/ 13/

13. Piaget, Jean. (1995) Abstração reflexionante; relações lógico-aritméticas e ordem das relações espaciais. Artes Médicas.

14. Carvalho, M. C. (2016). A Importância do Brincar na Construção de Conhecimentos de Crianças na PréEscola. Dissertação de Mestrado. Universidade Fernando Pessoa.

15. Piaget, J. (1999). Seis Estudos de Psicologia. 24. ed. Rio de Janeiro: Forense Universitária, $136 \mathrm{p}$.

16. Rosa, A. C. S., Ferriera, C. T. V., Nunes da Silva, D., Tibúrcio, N. M. S., Assis, R. D. C. \& Ferreira, W. A. S. (2018). The operative notions of volume and length: an exploratory study. Research, Society and Development, v. 7, n. 6, p.01-12.

17. Silva Filho, D. F. Diagnóstico da cobertura arbórea em tecido urbano do município de Piracicaba, SP. Relatório apresentado à Fundação de Estudos Agrários Luiz de Queiroz - FEALQ/Instituto de Planejamento de Piracicaba - IPPLAP. 2009. 22 p.

18. Freitas, W. K.; Magalhães, L. M. S.; Santana, C. A. A.; Pereira Junior, E. R.; Souza, L. C. M; Toledo, R. A. B.; Garção, B. R. (2020). Tree composition of urban public squares located in the Atlantic Forest of Brazil: A systematic review. Urban Forestry \& Urban Greening. 48:https://doi.org/10.1016/j.ufug.2019.126555

19. Nascimento, C. C.; Brasil, M. M.; Nascimento, C. S.; Barros, S. V. S. (2017). Estimativa da densidade básica da madeira de Eschweilera odora (Poepp.) Miers por espectroscopia no infravermelho próximo. Ciência da Madeira. 8(1): 42-53.

20. Bispo, L. F. P. (2017). Aproveitamento de Resíduos da Arborização Urbana para a Fabricação de Brinquedos. Trabalho de Conclusão de Curso. Universidade de São Paulo - Escola Superior de Agricultura Luiz de Queiroz.

21. Madar, A., Boşcor, D., Băltescu, C. \& Neacşu, A. (2012). Wooden Versus Plastic Toys. Proceedings of the International Scientific Conference Eco-Trend, IXth Edition. p. 254-260.

22. Rocha, E. L. B. (2018). Indicação de madeiras da caatinga para uso na produção de brinquedo. Natural Resources, v.8, n.1, p.9-16.
23. Goldstein, E. B. (2010). Sensation and Perception. Wadsworth: Cengage Learning.

24. Chaibub, T. (2017). A Experiência e o Ensino da Cor: apontamentos teóricos e práticos. Trabalho de conclusão de curso. Universidade de Brasília.

25. Jonauskaite, D., Dael, N. Chèvre, L., Althaus, B., Tremea, A., Charalambides, L. \& Mohr, C. (2019). Pink for Girls, Red for Boys, and Blue for Both Genders: Colour Preferences in Children and Adults. Sex Roles (2019) 80:630-642.

26. Chaigar, V. A. M. \& Madruga, E. B. (2015). Imaginários, cheiros, formas e cores de lugares de crianças e repercussões em adultos discentes de Pedagogia. Instrumento: R. Est. Pesq. Educ., Juiz de Fora, v.17, n.2. 